\title{
Original
}

\section{Myocardial Oxygen Consumption and Mitochondrial Membrane Potential in Post-Ischemic Myocardium}

\author{
Kazuaki Nishio, Noburu Konno, Yoshihisa Arata, \\ Ryuji UeDA, Katsumichi IIJIMA, Toshiki Iwata \\ and Takashi KATAGIRI
}

\begin{abstract}
Myocardial oxygen consumption $\left(\mathrm{MVO}_{2}\right)$ may be disproportionately high relative to contractile function in post-ischemic, reperfused myocardium. This study investigated the mechanism of dissociation between $\mathrm{MVO}_{2}$ and contractile function in post-ischemic, reperfused myocardium using isolated rat hearts. Mitochondrial dysfunction secondary to increased calcium uptake has been implicated as an important mediator of reperfusion injury in the heart. In post-ischemic, isovolumic, antegrade-perfused rat hearts, $\mathbf{M V O}_{2}$ rate and contractile function were studied in relation to mitochondrial function. Left ventricular pressure, coronary blood flow, and $\mathrm{MVO}_{2}$ were determined. Mitochondrial respiration and membrane potential were measured by polarography and flow cytometry. To examine the role of mitochondrial calcium uptake in ischemic reperfusion injury, isolated rat hearts perfused with ruthenium red (an inhibitor of calcium uptake) were compared to control perfused hearts. Hearts were subjected to 60 minutes of no-flow ischemia, followed by 60 minutes of reperfusion. At 15 minutes after the onset of reperfusion, there was poor recovery of left ventricular pressure to $54 \%$ of the control level, but $\mathrm{MVO}_{2}$ increased to $149 \%$ of the control. Addition of 2.5 $\mu \mathbf{M}$ ruthenium red to the perfusate resulted in a decrease in $\mathbf{M V O}_{2}$. The oxygen consumption rate in state 3 mitochondria decreased similarly following reperfusion both in control and in ruthenium red hearts. The mitochondrial membrane potential was reduced to $89 \%$ (logarithmic scale) after 15 minutes of reperfusion. This data suggests that the dissociation between $\mathbf{M V O}_{2}$ and contractile function following early reperfusion is partly caused by the repair of intracellular damage resulting from reduction of the mitochondrial membrane potential.
\end{abstract}

Key words : reperfusion injury, calcium overload, myocardial oxygen consumption, mitochondrial membrane potential

\section{Introduction}

In normal myocardium, there is a close relationship between contractile function and the oxidative metabolic rate ${ }^{1,2)}$. Recently several reports have indicated that this relationship may be altered after post-ischemic reperfusion ${ }^{3-5)}$. The mechanisms responsible for the

The Third Department of Internal Medicine, Showa University School of Medicine, 1-5-8, Hatanodai, Shinagawa-ku, Tokyo 142, Japan. 
dissociation between myocardial oxygen consumption $\left(\mathrm{MVO}_{2}\right)$ and contractile function in the early period after reperfusion are poorly understood. Periods of prolonged myocardial ischemia result in irreversible tissue damage and abnormalities of metabolic and mechanical function $^{5,6)}$. An important component of this injury may occur at the time of reperfusion and not during ischemia itself ${ }^{5,6)}$. It seems possible that this reperfusion injury is brought about by mitochondrial calcium loading during reperfusion. Mitochondrial calcium loading causes abnormalities of mitochondrial function and mitochondrial damage may lead to uncoupling of oxidative phosphorylation ${ }^{7)}$. These process abnormalities include changes in transmembrane ion transport ${ }^{8)}$ and futile metabolic cycling ${ }^{9)}$. Elevation of the cytosolic calcium concentration activates calcium transport systems at the inner mitochondrial membrane and at the sarcoplasmic reticulum, which may contribute to enhanced energy expenditure after reperfusion ${ }^{8)}$. Ruthenium red is a polysaccharide stain that inhibits mitochondrial calcium accumulation without any changes in the cytosolic calcium concentration. The present study was designed to investigate the mechanism of dissociation between $\mathrm{MVO}_{2}$ and contractile function in relation to mitochondrial calcium accumulation by using ruthenium red perfusion after reperfusion in rat hearts.

\section{Materials ans Methods}

\section{Perfusion protocol}

Male Wistar rats, weighing 250 to $400 \mathrm{~g}$, were anesthetized by intraperitoneal injection of pentobarbital. The hearts were excised and perfused in the Langendorff mode at an aortic pressure of $100 \mathrm{cmH}_{2} \mathrm{O}$ with Krebs-Henseleit cycle which was equilibrated with a mixture of $\mathrm{O}_{2}(95 \%)$ and $\mathrm{CO}_{2}(5 \%)$ at a temperature of $37^{\circ} \mathrm{C}$ and a $\mathrm{pH}$ of 7.4. A compliant latex balloon was inserted through the left atrium into the left ventricle to monitor myocardial function. The volume in the balloon was adjusted to $50 \mu \mathrm{l}$. Hearts were paced at $250 \mathrm{~b}$ eats $\cdot \min ^{-1}$. There were three phases of perfusion in this experiment. The first phase consisted of a 45 minutes control period allowing for experimental setup and acquisition of baseline measurements. The second phase consisted of 60 minutes of global myocardial ischemia, during which time all perfusate flow to the heart was stopped. The third phase of this study consisted of 60 minutes of reperfusion during which sequential collections of pulmonary artery effluent were done to determine myocardial coronary flow. The hearts were weighed at the end of the experiment. $\mathrm{MVO}_{2}$ was calculated by multiplying the coronary arteriovenous difference in the oxygen content by the myocardial blood flow. Ruthenium red was added to the perfusate at a final concentration of $2.5 \mu \mathrm{M}$ from the beginning of the first phase to the third phase.

\section{Mitochondrial respiration}

Mitochondria were prepared by a modification of the method of Sordahl and Stewart ${ }^{10)}$. The protein content was determined by Lowry's method ${ }^{11)}$ using BSA as a standard. Mitochondrial respiratory activity was determined with an oxygen electrode. The reaction medium contained $0.3 \mathrm{M}$ mannitol, $5 \mathrm{mM} \mathrm{MgCl}, 30 \mathrm{mM} \mathrm{KCl}$, and $10 \mathrm{mM} \mathrm{KH}_{2} \mathrm{PO}_{4}$ ( $\mathrm{pH}$ 7.2) at $30^{\circ} \mathrm{C}$, and succinate was used as a substrate.

\section{Measurement of mitochondrial membrane potential}

Mitochondrial membrane potential was measured according to Ronald's method, which 
was quoted by Emaus ${ }^{12)}$, by flow-cytometry using rhodamine 123. For flow-cytometric studies, mitochondria were suspended in a medium containing $0.3 \mathrm{M}$ mannitol, $10 \mathrm{mM} \mathrm{KCl}$, $5 \mathrm{mM} \mathrm{MgCl} 2$ and $10 \mathrm{mM} \mathrm{KH}_{2} \mathrm{PO}_{4}$ at $\mathrm{pH} 7.2$, as well as $1 \mathrm{mg} \cdot \mathrm{ml}^{-1}$ BSA where indicated. Mitochondria $\left(125 \mu \mathrm{g}\right.$ protein $\cdot \mathrm{ml}^{-1}$ ) were analyzed for their natural fluorescence and for their fluorescence after staining with aqueous rhodamine 123 (Sigma). Rhodamine 123 fluorescence was measured using an excitation wavelength of $488 \mathrm{~nm}$ and $400 \mathrm{~mW}$, while the final dye concentration was $5 \mathrm{nM}$. All measurements were made after a 30-minute incubation period in the presence of the dye and 10000 mitochondria particles were assessed in each analysis. The potential was shown as fluorescence on a logarithmic scale. The mitochondrial membrane potential was expressed as the ratio of the fluorescence value of perfused heart mitochondria divided by the control value.

\section{Statistical analysis}

Results are expressed as the mean \pm S.D. Statistical significance was evaluated by Student's t-test for paired or unpaired data and $\mathbf{P}$ values (two-tailed) were calculated. $\mathbf{P}<0.05$ was considered to be significant.

\section{Results}

\section{Hemodynamics}

Fig. 1A and 1B show myocardial oxygen consumption $\left(\mathrm{MVO}_{2}\right)$ and left ventricular systolic pressure (LVSP) in the control and the ruthenium red group. Values in the control group and ruthenium red group before ischemia were: $\mathrm{MVO}_{2} 1151 \pm 522,842 \pm 366 \mathrm{mmHg}$. $\mathrm{ml} \mathrm{min}^{-1} \mathrm{~g}^{-1}$; LVSP $13.5 \pm 3.5$ versus $26.5 \pm 6.9 \mathrm{mmHg} ; \mathrm{P}=0.0048 ; \mathrm{P}=0.25$. In the control group at 10 minutes after beginning reperfusion, $\mathrm{MVO}_{2}$ increased to $149 \%$ of the preischemic value $\left(1151 \pm 522\right.$ versus $\left.1715 \pm 325 \mathrm{mmHg} \cdot \mathrm{ml} \mathrm{min}^{1} \mathrm{~g}^{-1} ; \mathrm{P}=0.048\right)$, although contractile function continued to decrease to $54 \%$ (LVSP $13.5 \pm 3.5$ versus $7.3 \pm 4.2 \mathrm{mmHg}$; $\mathbf{P}=0.007$, indicating dissociation between $\mathrm{MVO}_{2}$ and contractility. In contrast, in the ruthenium red group, there was no increase in $\mathrm{MVO}_{2}$ as the contractile function decreased to $56 \%$ ( LVSP $26.5 \pm 6.8$ versus $16.2 \pm 11.3 \mathrm{mmHg} ; \mathrm{P}=0.016$ ) of the preischemia value.

Fig. 2 shows changes in myocardial contractility after ischemia and reperfusion. These changes were similar in both groups with contractility quickly dropping to zero when the heart became ischemic, and then returning to the baseline after reperfusion.

In our experimental model, the contraction was isovolumic and the beating rate was fixed by electrical pacing, thus the ratio of $\mathrm{MVO}_{2}$ divided by left ventricular systolic pressure (LVSP) is assumed to indicate the efficiency of the mechanical utilization of respiratory energy. Fig. 3 shows the changes in $\mathrm{MVO}_{2} / \mathrm{LVSP}$ as an index of contractile efficiency during ischemia-reperfusion. In the control group, $\mathrm{MVO}_{2} / \mathrm{LVSP}$ increased significantly to $203 \%$ of the preischemic level (from $141 \pm 17$ to $286 \pm 78 \mathrm{ml} \mathrm{min}^{-1} \mathrm{~g}^{-1} ; \mathrm{P}=0.035$ ) at 10 minutes after reperfusion, indicating a decrease in contractile efficiency, and after 30 minutes of reperfusion returned to the baseline. In the ruthenium red group, $\mathrm{MVO}_{2} / \mathrm{LVSP}$ decreaseed to $69 \%\left(28.5 \pm 8.9\right.$ to $\left.19.7 \pm 17.8 \mathrm{~min}^{-1} \mathrm{~g}^{-1} ; \mathbf{P}=0.035\right) 10$ minutes after reperfusion and gradually increased during reperfusion.

Coronary flow during the preischemic and reperfusion periods in the control and the ruthenium red treated group is shown in Fig. 4. In the control group, coronary flow was transiently increased after 10 minutes of reperfusion $\left(3.4 \pm 1.2\right.$ to $4.2 \pm 1.3 \mathrm{ml} \mathrm{min} \mathrm{m}^{-1} \mathrm{~g}^{-1}$; 


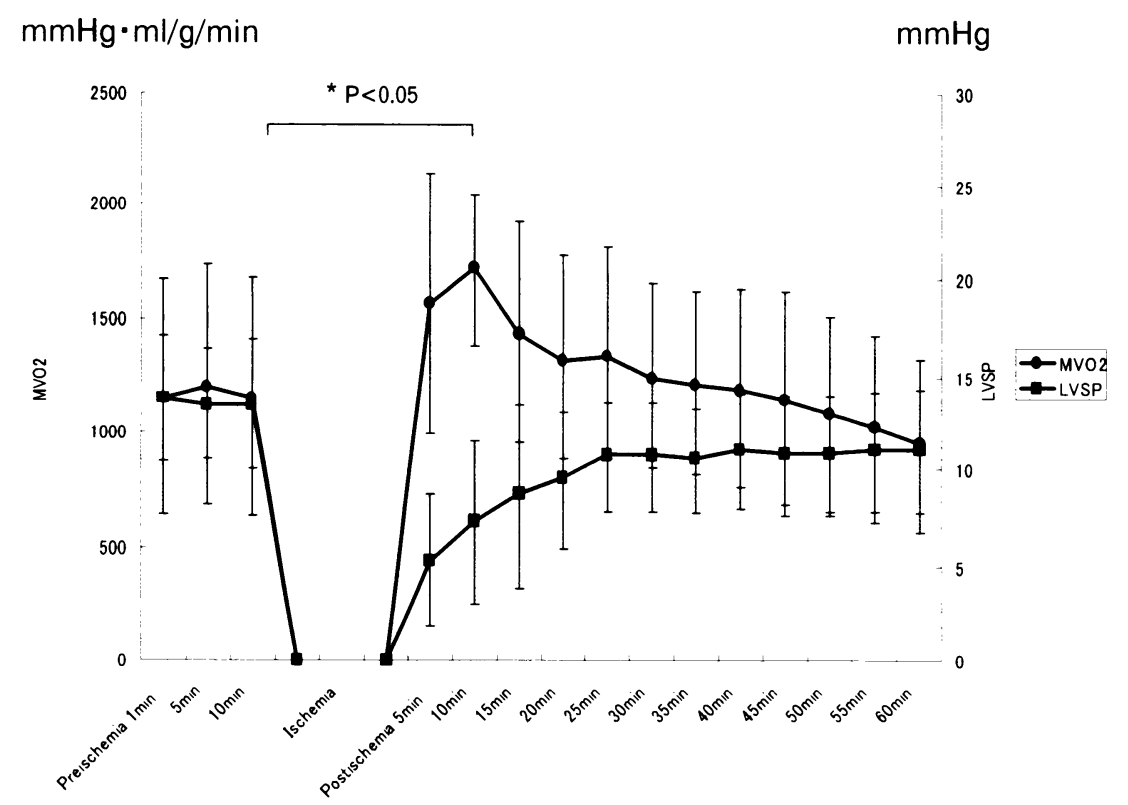

(A) Myocardial oxygen consumption $\left(\mathrm{MVO}_{2}\right)$ and left ventricular systolic pressure (LVSP) versus time.

$\mathrm{mmHg} \cdot \mathrm{ml} / \mathrm{g} / \mathrm{min}$

$\mathrm{mmHg}$

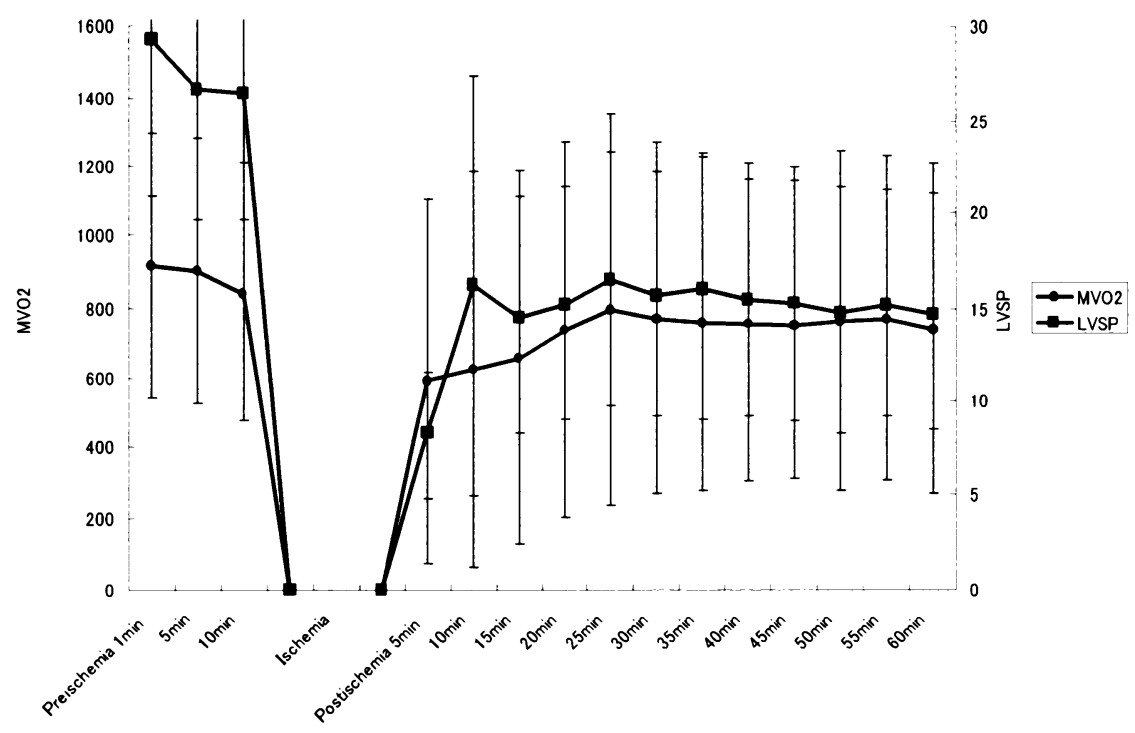

(B) $\mathrm{MVO}_{2}$ and LVSP in ruthenium red treated group versus time. ${ }^{*} \mathrm{P}<0.05$ versus preischemia ${ }^{* *} \mathrm{P}<0.01$ versus preischemia

Fig. 1.

$P=0.006$ ), indicating reactive hyperemia and returned to the preischemic baseline level. In the ruthenium red group, coronary flow significantly decreased after the beginning of reperfusion, indicating no reactive hyperemia $\left(2.3 \pm 1.1\right.$ to $\left.1.3 \pm 1.1 \mathrm{ml} \mathrm{min}^{-1} \mathrm{~g}^{-1} ; \mathrm{P}=0.024\right)$. 
$\mathrm{mmHg} / \mathrm{sec}$

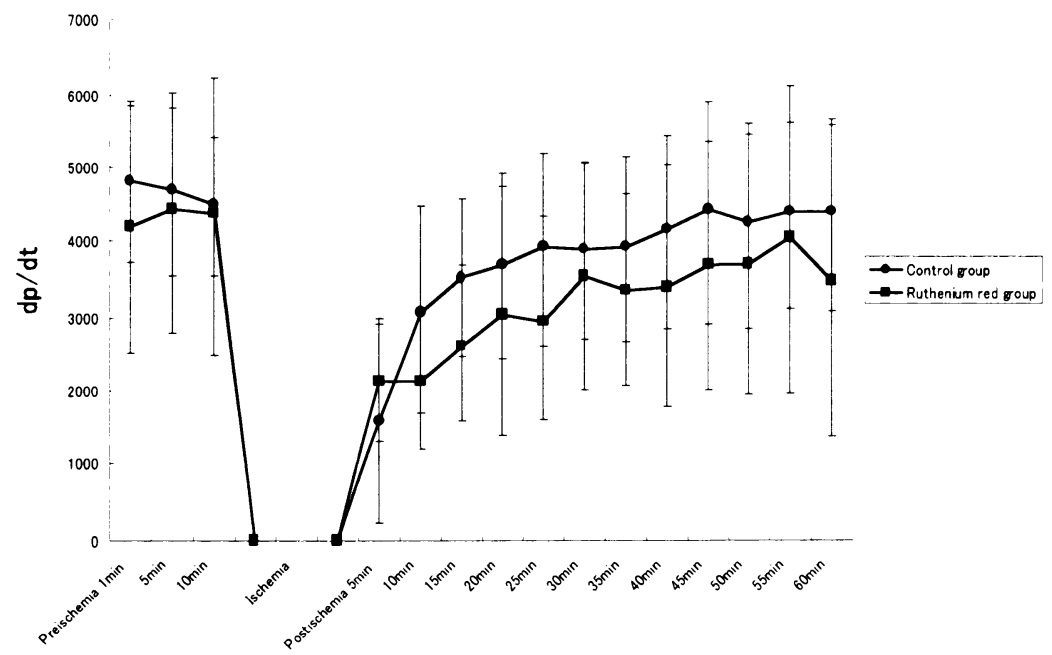

Fig. 2. Myocardial contractility

Contractility was determined by the peak positive time derivative of developed pressure $(\mathrm{dp} / \mathrm{dt})$ versus time.

$\mathrm{ml} / \mathrm{g} / \mathrm{min}$
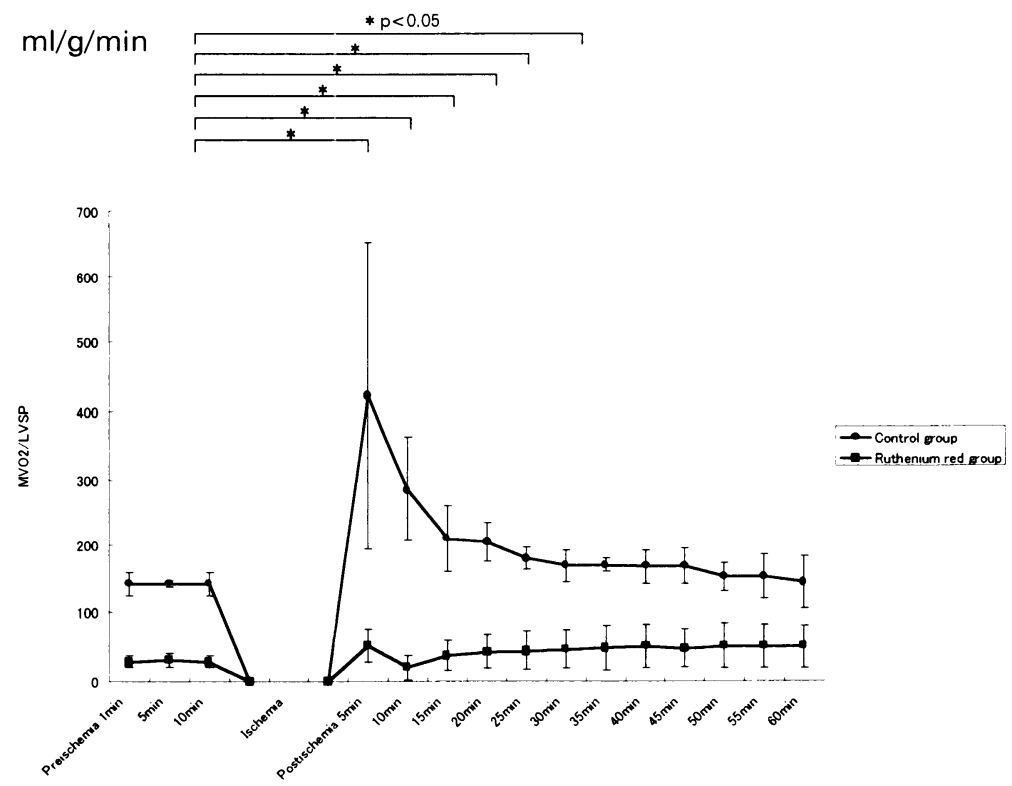

Fig. 3. Contractile efficiency

Myocardial oxygen consumption $\left(\mathrm{MVO}_{2}\right) /$ Left ventricular systolic pressure (LVSP) versus time. ${ }^{*} \mathrm{P}<0.05$

\section{Oxygen consumption rate in mitochondria}

The mitochondrial oxygen consumption rate in state 3 is shown in Fig. 5. The values of the oxygen consumption rate in state 3 were $319 \pm 62$ and $356 \pm 84 \mathrm{~m} \mu$ atoms $\mathrm{O} \mathrm{mg} \mathrm{protein}{ }^{-1}$ 
$\mathrm{ml} / \mathrm{min}$

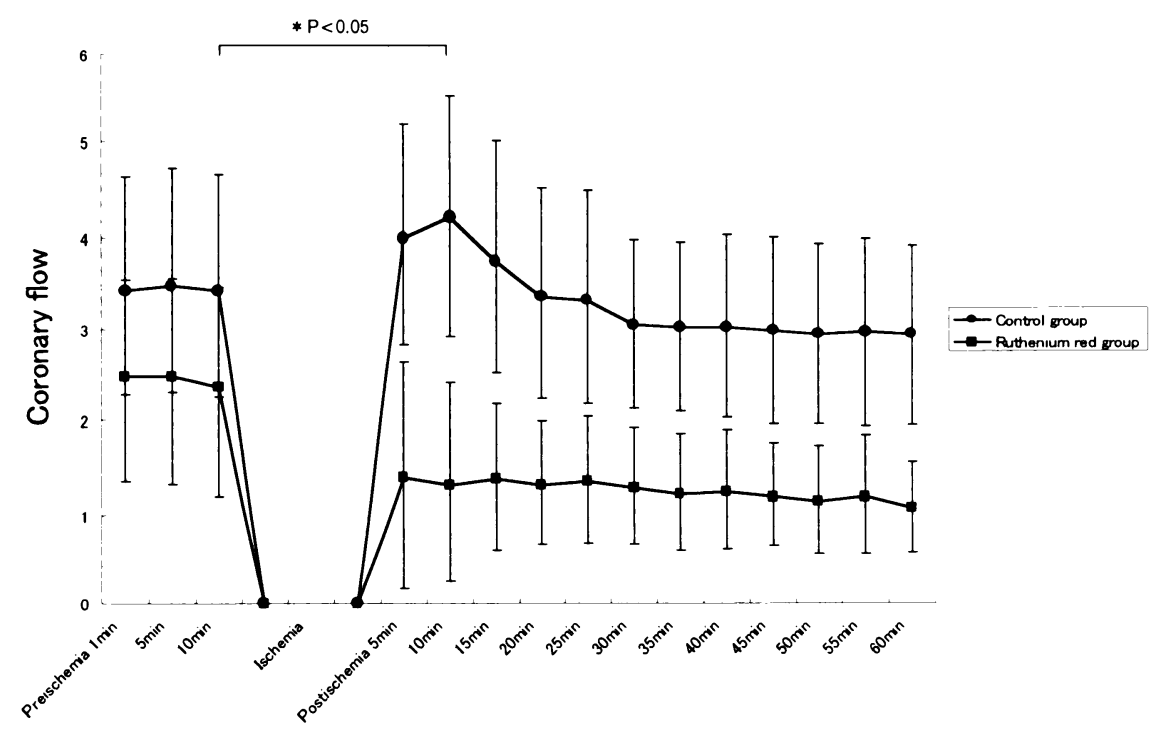

Fig. 4. Coronary flow rate $\left(\mathrm{ml} \cdot \mathrm{min}^{-1} \cdot \mathrm{g}^{-1}\right)$ versus time. ${ }^{*} \mathrm{P}<0.05$

$\mathrm{m} \mu$ Atoms $\mathrm{O} / \mathrm{mg}$ protein $/ \mathrm{min}$

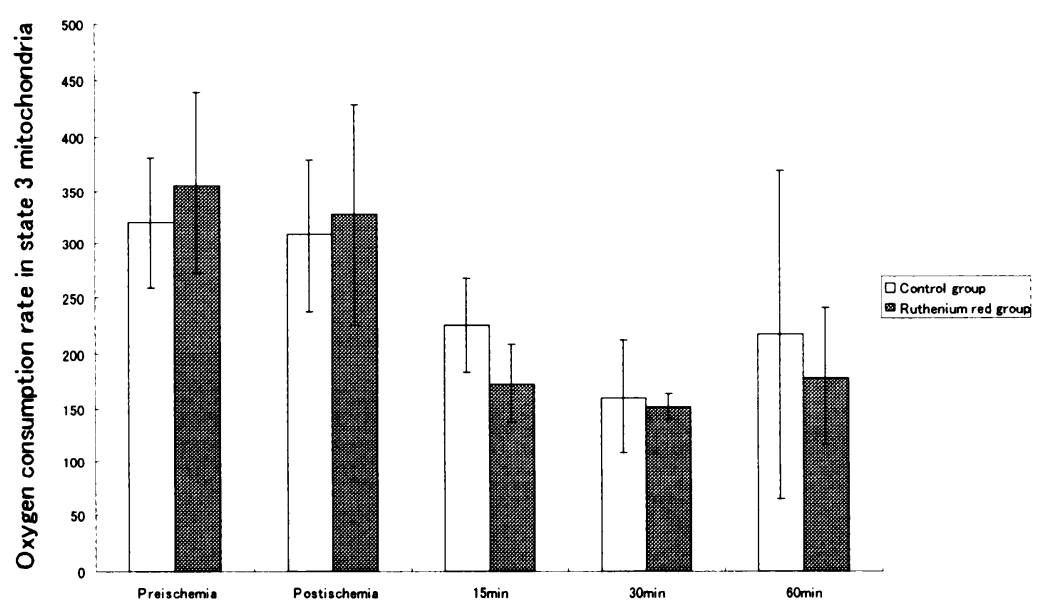

Fig. 5. Oxygen consumption rate in state 3 mitochondria.

$\min ^{-1}(\mathbf{P}=0.520)$, in the control group and the ruthenium red group, respectively. After 30 minutes of reperfusion following 60 minutes of ischemia, the mitochondrial respiration rate was decreased to $50 \%\left(319 \pm 62\right.$ to $161 \pm 52 \mathrm{~m} \mu$ atoms $\left.O \mathrm{mg} \operatorname{protein}^{-1} \min ^{-1} ; \mathrm{P}=0.0042\right)$ 


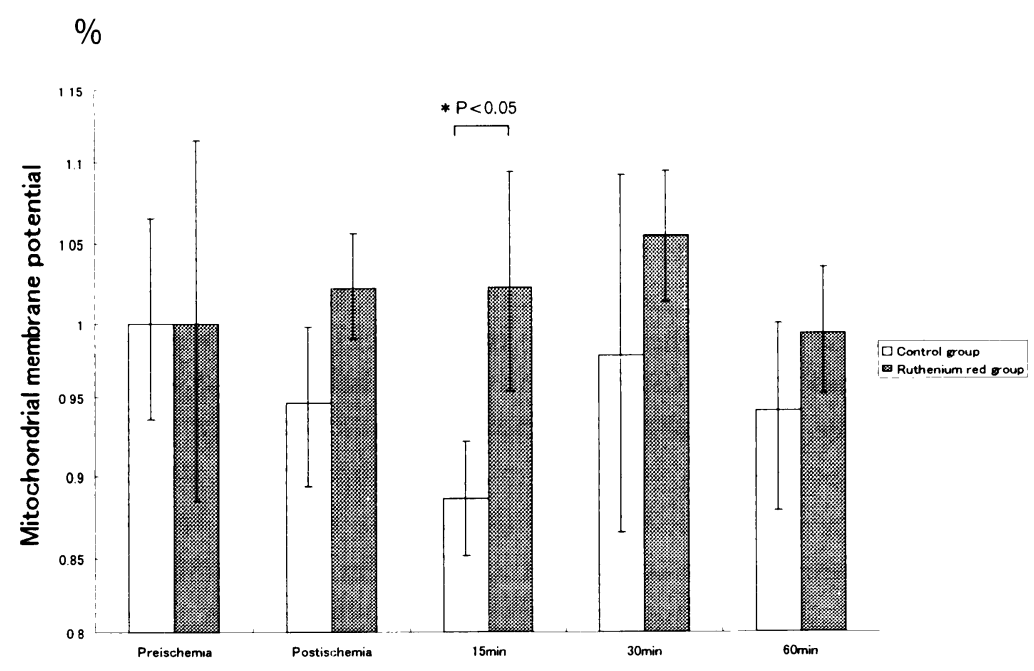

Fig. 6. Mitochondrial membrane potential (MMP) versus time.

MMP was expressed as the ratio of the fluorescence value of perfused heart mitochondria divided by the control value on a logarithmic scale. ${ }^{*} \mathrm{P}<0.05$

and $68 \%$ (356 \pm 84 to $153 \pm 12 \mathrm{~m} \mu$ atoms $\left.\mathrm{O} \mathrm{mg}_{\text {protein }}{ }^{-1} \mathrm{~min}^{-1} ; \mathrm{P}=0.002\right)$ in state 3 , in the control and the ruthenium red group, respectively. No significant difference was observed between the two groups.

\section{Mitochondrial membrane potential}

The mitochondrial membrane potential during the preischemic period and after reperfusion in both the control and the ruthenium red group is shown in Fig. 6 . In the control group, the mitochondrial membrane potential was reduced to $89 \%$ of the control value $(1.074 \pm 0.070$ to $0.952 \pm 0.038 \% ; \mathbf{P}=0.039)$ at 15 minutes of reperfusion and returned to the preischemic baseline level. In contrast, in the ruthenium red group, no reduction of the mitochondrial membrane potential was observed after reperfusion $(0.945 \pm 0.109$ to $0.958 \pm 0.066 \% ; P=0.877)$.

\section{Discussion}

Under physiological conditions, myocardial oxygen demand and supply are well balanced. However many investigators have demonstrated the dissociation between $\mathbf{M V O}_{2}$ and contractile function in post-ischemic reversibly injured tissue such as stunned myocardium ${ }^{1-4)}$. In isolated re-perfused heart, relatively high myocardial oxygen consumption is associated with depression in regional contractility in irreversibly injured myocardium after prolonged ischemia. Benzi and Lerch ${ }^{13)}$ showed dissociation between $\mathrm{MVO}_{2}$ and contractility after 60 minutes of ischemia in re-perfused rat hearts. Our study also demonstrated increased $\mathbf{M V O}_{2}$ while contractile function was decreased in the early phase of reperfusion after 60 minutes of ischemia. This dissociation means that postischemic myocardial oxygen utilization may be increased above physiological levels, indicating a decrease in contractile efficiency. Possible explanations for this phenomenon include uncoupling of oxidative phosphorylation, 
resulting in inefficient mitochondrial ATP production, or an increase in the cellular energy requirement for processes other than contraction.

In a previous study the mitochondrial respiratory function was unchanged in stunned myocardium ${ }^{14)}$, thus a relatively high $\mathrm{MVO}_{2}$ in the post-ischemic tissue has not been considered in relation to mitochondrial respiration uncoupling. In contrast, our results demonstrated a significant decrease in the mitochondrial respiration rate in the reperfused heart. Although in reperfused heart treated with ruthenium red, the mitochondrial respiration rate decreased while the $\mathrm{MVO}_{2}$ did not increase, we can postulate that the dissociation of $\mathrm{MVO}_{2}$ and contractile function in ischemic injured tissue is not secondary to mitochondrial uncoupling. An increase in non-contractile energy requirements seems to be more likely, perhaps related to an increase in ion pumping (i.e. extrusion of calcium from mitochondria in calcium overloaded myocytes) or an increase in the activity of calcium ATPase to maintain normal sequestration of calcium by the sarcoplasmic reticulum ${ }^{15)}$.

It is widely accepted that calcium contributes to cell injury caused by ischemia and reperfusion. Calcium influx results in the reduction of mitochondrial membrane potential, severely compromising mitochondrial function in the myocardium and triggers apoptotic events leading to cell demise ${ }^{16)}$. From a mitochondrial point of view, the first response is to maintain the mitochondrial membrane potential by using ATP $^{17)}$. Murata et al $^{18)}$ demonstrated that attenuation of mitochondrial calcium overload, as a consequence of partial mitochondrial membrane depolarization by mitochondrial ATP-sensitive potassium channels, underlies cardioprotection. Carafoli ${ }^{19)}$ has estimated that an increase of cytosolic calcium concentration from 1 to $10 \mu \mathrm{M}$ is associated with a more than 20-fold increase of the total mitochondrial calcium uptake per unit of time, whereas the corresponding value for the sarcoplasmic reticulum is less than doubled.

Ruthenium red is a hexavalent polysaccharide stain, which inhibits mitochondrial calcium transport without elevating of intracellular calcium ${ }^{5)}$, although the mechanism is unclear ${ }^{20)}$. There was no dissociation between myocardial oxygen consumption and contractile function and no decrease in the mitochondrial membrane potential during early reperfusion in the group with ruthenium red. This suggests the dissociation of $\mathbf{M V O}_{2}$ and contractility, at least partially, is caused by the accumulation of calcium in the mitochondria. Calcium loading into mitochondria may result in waste respiratory energy by forcing the mitochondrial membrane potential to release calcium to the matrix ${ }^{18,21)}$.

In conclusion, in this study the postischemic heart showed dissociation between an increase in $\mathrm{MVO}_{2}$ and a decrease in contractile function, and a decrease in the mitochondrial membrane potential in early reperfusion. Ruthenium red prevented the dissociation and the decrease in the mitochondrial membrane potential in the early stage after reperfusion. The dissociation is due, at least partially, to the accumulation of calcium in the mitochondria. The increase in $\mathrm{MVO}_{2}$ is caused by increased ion pumping resulting in the extrusion of calcium from mitochondria in the postischemic myocardium.

\section{Acknowledgments}

The authors are very grateful to Seiji Ito M.D., Eiichi Geshi M.D., and Kunihiko Fukuchi M.D. for their kind guidance and encouragement of this work. 


\section{References}

1) Sarnoff SJ, Braunwald E, Welch GH Jr, Case RB, Stainsby WN and Macruz R: Hemodynamic determinants of oxygen consumption of the heart with special reference to tension-time index. Am J Physiol 192:148-156 (1958)

2) Neely JR, Liebermeister H, Battyersby EJ and Morgan HE: Effect of pressure development on oxygen consumption by isolated rat hearts. Am J Physiol 212 : 804-814 (1967)

3) Stahl LD, Weiss HR and Becker LC: Myocardial oxygen consumption, oxygen supply/demand heterogeneity, and microvascular patency in regionally stunned myocardium. Circulation $77: 865-872$ (1988)

4) Laxson DD, Homans DC, Dai X-Z, Sublett E and Bache RJ : Oxygen consumption and coronary reactivity in postischemic myocardium. Circ Res 64 : 9-20 (1989)

5) Peng CF, Kane JJ, Straub KD and Murphy ML : Improvement of mitochondrial energy production in ischemic myocardium by in vivo infusion of ruthenium red. J Cardiovasc Pharmacol 2 : 45-54 (1980)

6) Bourdillon PD and Poole-Wilson PA: Effects of ischemia and reperfusion on calcium exchange and mechanical function in isolated rabbit myocardium. Cardiovasc Res 15 : 121-130 (1981)

7) Huang $\mathrm{XQ}$ and Liedtke AJ : Alterations in fatty acid oxidation in ischemic and reperfused myocardium. Mol Cell Biochem 88 : 145-153 (1989)

8) Kusuoka H, Koretune Y, Chacko VP, Weisfeldt ML and Marban E: Excitation-contraction coupling in postischemic myocardium : Does failure of activator $\mathrm{Ca}^{2+}$ transients underlie stunning? Circ Res 66 : 1268-1276 (1990)

9) Trach V, Buschmans-Denkel E and Schaper W: Relation between lipolysis and glycolysis during ischemia in the isolated rat heart. Basic Res Cardiol $81: 454-464$ (1986)

10) Sordahl LA and Stewart ML: Mechanism (s) of altered mitochondrial calcium transport in acutely ischemic canine hearts. Circ Res $47: 814-820$ (1980)

11) Lowry $\mathrm{OH}$, Rosenbrough NJ, Farr $\mathrm{AL}$ and Randall RJ : Protein measurement with the Folin phenol regent. J Biol Chem 193 : 265-275 (1951)

12) Emaus RK, Grunwald R, and Lemasters JJ: Rhodamine 123 as a probe of the transmembrane potential in isolated rat-liver mitochondria: spectral and metabolic properties. Biochim Biophys Acta 850 : 436-448 (1986)

13) Benzi RH and Lerch R: Dissociation between contractile function and oxidative metabolism in postischemic myocardium. Attenuation by ruthenium red administered during reperfusion. Circ Res $71: 567-576$ (1992)

14) Kubler W and Katz AM : Mechanism of early "pump" failure of the ischemic heart: possible role of ATP depletion and inorganic phosphate accumulation. Am J Cardiol $40: 467-471$ (1977)

15) Krause $S$ and Hess ML: Characterization of cardiac sarcoplasmic reticulum dysfunction during short - term, normothermic, global ischemia. Circ Res 55 : 176-184 (1984)

16) Xu M, Wang Y, Ayub A and Ashraf $M$ : Mitochondrial $K$ (ATP) channels activation reduces anoxic injury by restoring mitochondrial membrane potential. Am J Physiol 281: H1295-H1303 (2001)

17) Di Lisa F, Menabo $R$, Canton $M$ and Petronilli V: The role of mitochondria in the salvage and the injury of the ischemic myocardium. Biochem Biophys Acta $1366: 69-78$ (1998)

18) Murata M, Akao M, O'Rourke B and Marban NE: Mitochondrial ATP-sensitive potassium channels attenuate matrix $\mathrm{Ca}(2+)$ overload during simulated ischemia and reperfusion: possible mechanism of cardioprotection. Circ Res 89 : 891-898 (2001)

19) Carafoli E: The homeostasis of calcium in heart cells. J Mol Cell Cardiol 17 : 203-212 (1985)

20) Ferrari $R$, di Lisa F, Raddino $R$ and Visioli $O$ : The effects of ruthenium red on mitochondrial function during post-ischemic reperfusion. J Mol Cell Cardiol 14 : 737-740 (1982)

21) Frei B and Richter C: Mono (ADP-ribosylation) in rat liver mitochondria. Biochemistry 27 : $529-535$ (1988)

[Received August 19, 2002 : Accepted December 12, 2002] 